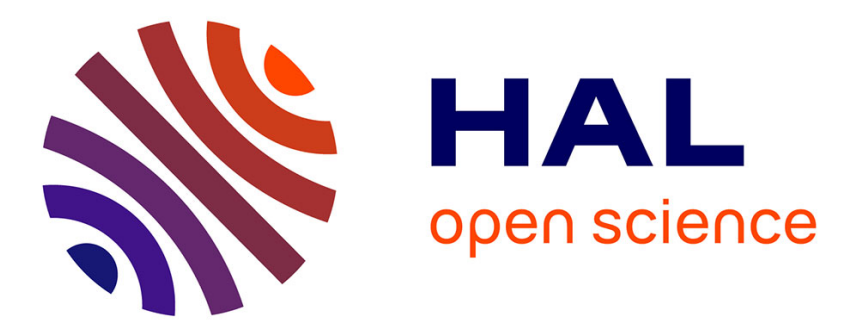

\title{
A nonlinear multiobjective approach for the supplier selection, integrating transportation policies
}

\author{
Aicha Aguezzoul, Pierre Ladet
}

\section{To cite this version:}

Aicha Aguezzoul, Pierre Ladet. A nonlinear multiobjective approach for the supplier selection, integrating transportation policies. Journal of Modelling in Management, 2007, 2 (2), pp.157-169. 10.1108/17465660710763434 . hal-00366486

\section{HAL Id: hal-00366486 https://hal.science/hal-00366486}

Submitted on 9 Mar 2009

HAL is a multi-disciplinary open access archive for the deposit and dissemination of scientific research documents, whether they are published or not. The documents may come from teaching and research institutions in France or abroad, or from public or private research centers.
L'archive ouverte pluridisciplinaire HAL, est destinée au dépôt et à la diffusion de documents scientifiques de niveau recherche, publiés ou non, émanant des établissements d'enseignement et de recherche français ou étrangers, des laboratoires publics ou privés. 


\title{
A nonlinear multiobjective approach for the supplier selection, integrating transportation policies
}

\author{
Aicha Aguezzoul ${ }^{1}$, Pierre Ladet $^{2}$ \\ ${ }^{1}$ UFR ESM-IAE \\ 3, place Edouard BRANLY, Technopôle Metz 2000, 57070 METZ \\ Phone: +33038756 37 86, Fax: +33038756 3779 \\ ${ }^{2}$ Laboratoire Automatique de Grenoble \\ BP 46, rue de la houille blanche, Saint Martin d'Hères Cedex, France \\ Phone: +330476827113, Fax: +330476826388 \\ aicha.aguezzoul@univ-metz.fr, pierre.ladet@inpg.fr
}

\begin{abstract}
Purpose - The impact of transportation on the supplier selection has received a very scant attention in the literature. This is a great limitation because splitting orders across multiple suppliers will lead to smaller transportation quantities which will likely imply larger transportation cost. Moreover, transportation and inventory elements are highly interrelated and contribute most to the total logistics costs. This paper seeks to present a nonlinear multiobjective programming approach of selecting suppliers and allocating the order quantity among them, taking into account transportation.

Design/methodology/approach - The model considers the total product cost and the lead-time as the criteria to minimize simultaneously.

Findings - The total cost is the sum of transportation, inventory and ordering costs. The constraints related to suppliers and buyer are also considered in the model. The model is solved several times, evaluating various scenarios. Each scenario depends on the shipment type used between the suppliers and the buyer.

Originality/value - This paper fills a gap in the literature by comprehensively examining the role of transportation in determining the optimal number of suppliers and the portion of the order to allocate to each one.

Keywords - Supplier evaluation, Freight forwarding, Inventory management, Supply chain management.
\end{abstract}

Paper type - Research paper

\section{Introduction}

In today's increasing competitive business world, the suppliers' selection is one of the most critical activities of a company and a strategic purchasing decision that commits significant resources ( $40 \%$ to $80 \%$ of total product cost) and impacts the total performance of the firm. The studies in that field show that this decision is a complex process involving various criteria such as procurement cost, product quality, delivery performance, etc. These criteria, which vary according to various factors such as the type of the product, the activity of the company, etc, are often in conflict with one another. For example, low prices can be offset by poor quality or delivery reliability. Therefore, the supplier selection is an inherently multiobjective decision. Dickson (1966) has identified at least 23 criteria in his empirical study in various vendor selection problems. Moreover, a review of 74 articles by Weber et al. (1991) obtained similar 
results and showed that several approaches have been suggested to take into account the multiobjective nature of the decision problem. These approaches may be grouped into three categories, which are: linear weighting models, mathematical programming models and statistical/probabilistic approaches. However, that study identified very few articles that have proposed mathematical programming techniques to analyze supplier selection decision. Over the past few years, other techniques are suggested in the literature. We can mention: interpretive structural modeling (Mondal and Deshmukh, 1994), expert system (Vokurka et al., 1996), data envelopment analysis (Weber, 1996; Liu et al., 2000), multi-objective programming (Weber et al., 2000), Analytic Network Process (ANP) model (Sarkis and Srinivas, 2002), integrated approach (Youssef et al., 1996; Çebi and Bayraktar, 2003; Teng and Jaramillo, 2005), etc. Moreover, other studies were interested in the choice between sole and multiple sourcing. They indicate that splitting an order among several vendors promotes competitive bidding, reduces the risk of supplier nonperformance and can offer savings in inventory costs (Goffin et al., 1997; Sedarage et al., 1999).

None of the studies cited above consider, in an explicit way, the impact of transportation on the supplier selection decision. This is a great limitation because splitting orders across multiple suppliers will lead to smaller transportation quantities which will likely imply larger transportation cost. Moreover, transportation and inventory elements are highly interrelated and contribute most to the total logistics costs: costs incurred in the suppliers while the products wait to be shipped, costs represented by the products in transit and costs incurred in the buyer while the products wait to be used. Finally, transportation has a direct impact on the lead-time, which affects the firm's total cycle time.

The most important articles that have addressed the problem of multi-sourcing, in particular dual sourcing and transportation are described below:

Hong and Hayya (1992) have discussed reducing lot size in the JIT purchasing environment with multiple vendors. A nonlinear programming problem is formulated and the objective function is to minimize the aggregate ordering and holding costs under delivered cost and quality constraints. Transportation cost is not formulated explicitly in the model. For multiple sourcing, the model gives the optimal selection of suppliers and the size of the split orders whereas, for the single sourcing, it determines the optimal number of deliveries.

Ganeshan et al. (1999) examine the dynamics of a supply chain that has the option of using two suppliers: one reliable and other unreliable. The unreliable supplier is characterized with long lead-time. Although the use of that supplier might warrant higher inventory and transportation costs, it's attractive to the firm because he is willing to provide a discount on the purchase price. In that study, the authors present a model, which minimize the sum of purchasing, ordering, holding and transportation costs. Holding cost includes cycle-stock, in-transit stock and safety stock carrying costs. The expected shortage per replenishment cycle is the only constraint of the model. A simple heuristic is used to determine the level of discount that needs to be offered and the portion of the order that should be placed with secondary supplier.

Tyworth and Ruiz-Torres (2000) investigate the role of transportation in the sole versus dual sourcing decision. They present a model, which minimizes the sum of purchasing, ordering, storage and transportation costs. No constraints are defined in the model. They demonstrated that dual supplier sourcing could yield savings under some conditions on supplier price, annual demand, lead-time performance and line-haul distance.

More recently, Ghodsypour and O'Brien (2001) proposed a mixed integer non-linear programming model, which takes into account the total cost of logistics. The total cost includes ordering, holding and purchasing costs. The cost of transport is not clarified even if it is 
mentioned in the paper. The model considered supplier capacities, buyer demand and quality constraints.

In these various types of research, stocks in the entire transportation network (suppliers, transit and buyer) are not clarified and the effects of transportation on the supplier selection problem are not considered. The contribution of our paper is the integration of all these elements in the multi-objective programming (MOP) approach that we propose. The MOP model was first introduced by Weber and Ellram (1993) as a technique for selecting vendors in procurement environment characterized by multiple conflicting criteria. Our first work in this field was published in some conferences (Aguezzoul and Ladet 2004a; 2004b; 2004c). In this article, we added other bibliographical studies, modified the model by integrating the distances between the buyer and the suppliers and finally improved the data-processing program corresponding to the model suggested.

Then, the objectives to minimize in the model are total cost and lead-time criteria under suppliers, buyer and transportation constraints. Total cost includes transportation, ordering and inventory costs. Total purchasing cost is not considered here and we suppose that the product, which is purchased over a given horizon of time, has the same unit price from all the suppliers. Let us note that cost and lead-time criteria are chosen here because they are used in literature. Moreover, they are much related to the transport policies.

The model simultaneously determines the optimal number of suppliers to employ and the order quantities to allocate to them, taking into account the transportation. The model is validated using a numerical example.

This paper is structured as follows. In the next section, we present the mathematical form of our model. In section 3, we give a solution methodology of our multiobjective model. Section 4 reports the results of computational experiments made using MATLAB, software specialized in optimization, to solve the model. The last section contains concluding remarks.

\section{Model formulation}

In a multiple sourcing network, a buyer must make a choice among several suppliers and decide on the order quantities to split among them. The model proposed considers the criteria, which take into account transportation, namely: total product cost and lead-time. The objectives to minimize simultaneously are these two criteria. Total cost includes ordering, transportation and storage costs subject to capacity and lead-time required by each supplier and lead-time imposed by the buyer. We assume that the demand of the buyer is known and constant and that the transportation capacity is unlimited.

Let's define the following variables and formulas:

$\mathrm{n}=$ number of suppliers

$\mathrm{D}=$ unit time demand of buyer

$\mathrm{Q}=$ ordered quantity to all suppliers in each period

$\mathrm{Q}_{\mathrm{i}}$ : ordered quantity to $i^{\text {th }}$ supplier in each period

$\mathrm{A}_{\mathrm{i}}=$ ordering cost per order, of $i^{\text {th }}$ supplier

$\mathrm{P}_{\mathrm{i}}=$ purchase price of $i^{\text {th }}$ supplier

$\mathrm{C}_{\mathrm{i}}=$ production capacity of $i^{\text {th }}$ supplier

$1_{\mathrm{i}}=$ lead-time required by $i^{\text {th }}$ supplier

$\mathrm{T}_{\mathrm{i}}=$ average transit time from $i^{\text {th }}$ supplier to buyer

$\mathrm{L}=$ lead-time imposed by the buyer

$\mathrm{r}=$ holding rate of the buyer 
$\mathrm{r}_{\mathrm{i}}=$ holding rate of $i^{\text {th }}$ supplier

$\mathrm{rt}_{\mathrm{i}}=$ in-transit holding rate of $i^{t h}$ supplier

$\mathrm{d}_{\mathrm{i}}=$ distance from $i^{\text {th }}$ supplier to buyer

$\mathrm{Cf}_{\mathrm{i}}=$ fixed shipping cost of $i^{\text {th }}$ supplier

$\mathrm{Cv}_{\mathrm{i}}=$ variable shipping cost of $i^{\text {th }}$ supplier

Decision variables:

$\mathrm{X}_{\mathrm{i}}=$ fraction of $\mathrm{Q}$ allocated to $i^{\text {th }}$ supplier

$Y_{i}=\left\{\begin{array}{l}1 \text { if } X_{i} \succ 0\left(i^{\text {th }} \text { supplier is selected }\right) \\ 0 \text { if } \mathrm{X}_{\mathrm{i}}=0\end{array}\right.$

In addition, $\mathrm{D} / \mathrm{Q}$ is the number of periods during the time considered.

The total cost $\left(\mathrm{C}_{\text {total }}\right)$ can be written as:

$$
\mathrm{C}_{\text {total }}=\sum_{i=1}^{n}\left[(D / Q)\left(d_{i} C f_{i} Y_{i}+Q X_{i} C v_{i}\right)+(D / Q) A_{i} Y_{i}+D X_{i} P_{i}\left(r t_{i} T_{i}+\left(r_{i}+r\right) X_{i} Q / 2 D\right)\right]
$$

The first term in this expression is the total transportation cost. We use the modeling (Cf/Q + Cv) suggested by Hall (1985). The fixed shipping cost Cf is independent of a load and includes cost of stop and cost per unit distance. The variable shipping cost $\mathrm{Cv}$ is a cost per load and it's independent of the distance covered. The second term represents the total ordering cost. $A_{i}$ is restricted to traditional (non-transportation) ordering and inspection cost elements. The last term is the total inventory cost. In a transportation network, inventory includes items waiting to be shipped from each supplier, items in transit to buyer and items waiting to be used by buyer. That supposes that each supplier produces items at a constant rate and the production planning is synchronized with that of transport. The average time required to $i^{\text {th }}$ supplier to produce a shipment of size $\mathrm{Q}_{\mathrm{i}}$ is $\mathrm{Q}_{\mathrm{i}} / \mathrm{D}$. Each item in the load waits on average half of this time before being shipped $\mathrm{Q}_{\mathrm{i}} / 2 \mathrm{D}$. After arriving, each item waits on average $\mathrm{Q}_{\mathrm{i}} / 2 \mathrm{D}$ before being used. The average time spent by an item from $i^{\text {th }}$ supplier to buyer is $\mathrm{Q}_{\mathrm{i}} / \mathrm{D}+\mathrm{T}_{\mathrm{i}}$ (Burns et al., 1985).

As $\mathrm{Q}$ is the optimum order quantity, it can be calculated by using the derivative of $\mathrm{C}_{\text {total }}$ :

$$
\frac{\partial \mathrm{C}_{\text {total }}}{\partial Q}=0 \Rightarrow Q=\sqrt{2 D\left(\sum_{i=1}^{n}\left(A_{i}+d_{i} C f_{i}\right) Y_{i}\right) / \sum_{i=1}^{n} P_{i} X_{i}^{2}\left(r_{i}+r\right)}
$$

By substituting for $\mathrm{Q}$ in $\mathrm{C}_{\text {total }}$, it becomes:

$$
\mathrm{C}_{\text {total }}=\sqrt{2 D\left(\sum_{i=1}^{n}\left(A_{i}+d_{i} C f_{i}\right) Y_{i}\right)\left(\sum_{i=1}^{n} P_{i} X_{i}^{2}\left(r_{i}+r\right)\right)}+\sum_{i=1}^{n} D X_{i}\left(r t_{i} T_{i} P_{i}+C v_{i}\right)
$$

An appropriate aggregate performance measure for delivery to the buyer is given by Pan (1989) in the expression (1b) below:

$$
L T_{\text {total }}=\sum_{i=1}^{n} l_{i} X_{i}
$$

This expression must by less than the lead-time imposed by the buyer. This implies that the long lead-time of one supplier is compensated by the short lead-time of other suppliers. 
The mathematical formulation of the nonlinear multi-objective program model (NMOP) is given as follow:

$$
\begin{aligned}
& \operatorname{Min} \mathrm{Z}=\left(\mathrm{C}_{\text {total }}, \mathrm{LT}_{\text {total }}\right) \\
& \text { S. T. } \\
& X_{i} D \leq C_{i} \quad i=1, n \\
& \sum_{i=1}^{n} l_{i} X_{i} \leq L \\
& \sum_{i=1}^{n} X_{i}=1 \\
& \varepsilon Y_{i} \leq X_{i} \leq Y_{i} \quad i=1, n \\
& Y_{i}=0,1 \quad i=1, n
\end{aligned}
$$

Equation (1) specifies the multiobjective function whose components expressions are given by equations (1a) and (1b). Constraints (2) represent the supplier production capacity restriction. Constraint (3) is an aggregate performance measure for delivery for all suppliers. This expression is given by several authors (Chaudhry et al., 1993; Pan, 1989; Jayaraman et al., 1999) and must by less than the lead-time imposed by the buyer. This implies that the long lead-time of one supplier is compensated by the short lead-time of other suppliers,

Constraint (4) indicates that demand is placed with the set of $n$ suppliers. Constraints (5) require that an order is placed with a supplier if only he is selected; $\varepsilon$ is a positive number, slightly greater than zero. Constraints (6) impose binary requirements on the $\mathrm{Y}_{\mathrm{i}}$ variables.

\section{Solution methodology}

The multiobjective programming is often used to find a compromised solution, which simultaneously satisfy a number of design criteria. In solving the multiobjective programming problems, classical methods reduce them into a single objective of minimizing a weighted sum of deviations from goals. In our case and since the cost and lead-time criteria have different orders in magnitude, we have normalized the objectives by using the absolute values of the relative variations of each objective compared to its goal. Thus, the multiobjective function (1) can be rewritten as:

$$
\operatorname{MinZ}=w \frac{\left|\left(\sqrt{2 D\left(\sum_{i=1}^{n}\left(A_{i}+d_{i} C f_{i}\right)\left(\sum_{i=1}^{n} P_{i} X_{i}^{2}\left(r_{i}+r\right)\right)\right.}+\sum_{i=1}^{n} D X_{i}\left(r t_{i} T_{i} P_{i}+C v_{i}\right)\right)-G 1\right|}{G 1}+(1-w) \frac{\left|\sum_{i=1}^{n} l_{i} X_{i}-G 2\right|}{G 2}
$$

This equation is a single objective function and our NMOP can be solved as a single objective optimization problem subject to constraints (2)-(6). G1, G2, w and (1-w) respectively are the cost, lead-time goals and the weighting factors for the absolute values of the relative variations of each criterion.

To find G1, we solve the model in section 2 by considering the cost as the only objective function $\left(\mathrm{Z}=\mathrm{C}_{\text {total }}\right)$, even thing for $\mathrm{G} 2\left(\mathrm{Z}=\mathrm{LT}_{\text {total }}\right)$. 
The next section presents a numerical example to evaluate the model. All results presented are generated on a personal Compaq computer (Intel Pentium IV, $2.40 \mathrm{GHz}$ ) using Matlab version 6.5, a high-performance language that offers the optimization Toolbox as fmincon that performs minimization on general nonlinear functions.

The model is solved several times, evaluating various scenarios. Each scenario depends on the type of shipment used to move the products from suppliers to buyer.

\section{Numerical example}

In this section, we first study the performance of the model by representing the CPU time in function of the number of suppliers and then, present a case study of three suppliers who have capacities limited. Two types of shipment are used: a TruckLoad (TL) and a Less than TruckLoad (LTL), characterized respectively by the in-transit holding rate $10 \%$ and $12 \%$, the variable shipping cost 0 and 0.05 and the fixed shipping cost $1.32 \$ / \mathrm{mile}$ and $0.15 \$ / \mathrm{mile}$.

The demand of the buyer is 1000 per week, $r=20 \%$, the maximum accepted lead-time is 3 days, the ordering, the purchasing costs and the holding rate of each supplier are respectively $10 \$, 5 \$$ and $20 \%$. The capacities of the three suppliers are respectively 900, 800 and 700 when their distances to buyer are respectively 100, 150 and 200 miles. In these experiments, we take $\mathrm{a}=$ 0.001 by supposing that $0.1 \%$ is the minimum percentage of the demand that the buyer will order to a supplier (see constraint 5).

The model is then computing under five scenarios, each depending upon a shipment type used by each supplier, as follows:

- Scenario 1: each supplier uses a LTL,

- Scenario 2: each supplier uses a TL,

- Scenario 3: supplier 1 uses a TL while suppliers 2 and 3 each use LTL,

- Scenario 4: supplier 2 uses a TL while suppliers 1 and 3 each use LTL,

- Scenario 5: supplier 3 uses a TL while suppliers 1 and 2 each use LTL.

Table I contains other information on the suppliers, according to whether they use one or the other type of shipment.

"Take in Table I"

Table I: Supplier information

\begin{tabular}{ccccc}
\hline & & Supplier 1 & Supplier 2 & Supplier 3 \\
\hline \multirow{2}{*}{ Lead time (days) } & LTL & 1.43 & 2.14 & 2.86 \\
& TL & 0.57 & 0.86 & 1.14 \\
Transit time & LTL & 0.14 & 0.21 & 0.29 \\
(weeks) & TL & 0.06 & 0.09 & 0.11 \\
\hline
\end{tabular}

Table II gives the CPU time, which includes the generation, compilation and execution times in seconds, to provide an optimal solution for each value of $\mathrm{n}$. The data on the 10 suppliers are taken here in a random way.

"Take in Table II" 
Table II: Computational time in CPU seconds

\begin{tabular}{cc}
\hline $\mathrm{n}$ & CPU (seconds) \\
\hline 2 & 0.97 \\
3 & 1.58 \\
4 & 1.70 \\
5 & 4.48 \\
6 & 22.19 \\
7 & 63.92 \\
8 & 196.26 \\
9 & 538.66 \\
10 & 1827.61 \\
\hline
\end{tabular}

This time appears to grow exponentially in the number of suppliers, especially for value 7 of $n$. In this case, CPU time varies from 1 minute for $n=7$ to 30 minutes for $n=10$. This increase is attributed to the combinations of binary variables $Y_{i}\left(2^{n}\right)$. But we can conclude that our model can be solved in a rather reasonable amount of time.

For each of the five scenarios referred to above, table III respectively gives the values of G1, $\mathrm{G} 2$ and other computational results corresponding to each goal. $\mathrm{LT}_{\text {total }}$ * and $\mathrm{C}_{\text {total }}$ * respectively represents lead-time and total cost for G1 and G2.

"Take in Table III"

Table III: Computational results of G1 and G2

\begin{tabular}{ccccccccccc}
\hline & \multicolumn{2}{c}{ Scenario 1 } & \multicolumn{2}{c}{ Scenario 2 } & \multicolumn{2}{c}{ Scenario 3 } & \multicolumn{2}{c}{ Scenario 4 } & \multicolumn{2}{c}{ Scenario 5 } \\
\hline $\mathrm{X} 1$ & 0.54 & 0.90 & 0.51 & 0.90 & 0 & 0.90 & 0.58 & 0.20 & 0.54 & 0.30 \\
$\mathrm{X} 2$ & 0.46 & 0.10 & 0.49 & 0.10 & 0.54 & 0.10 & 0 & 0.80 & 0.46 & 0 \\
$\mathrm{X} 3$ & 0 & 0 & 0 & 0 & 0.46 & 0 & 0.42 & 0 & 0 & 0.70 \\
$\mathrm{Q}$ & 219 & 170 & 583 & 453 & 251 & 315 & 233 & 402 & 219 & 499 \\
$\mathrm{G} 1$ & 662.69 & & 1256.05 & & 802.31 & & 731.62 & & 662.69 & \\
$\mathrm{LT}_{\text {total }} *$ & 1.76 & & 0.71 & & 2.47 & & 2.03 & & 1.76 & \\
$\mathrm{G} 2$ & & 1.50 & & 0.60 & & 0.73 & & 0.97 & & 1.23 \\
$\mathrm{C}_{\text {total }} *$ & & 796.73 & & 1591.33 & & 1171.25 & & 1268.58 & 1307.96 \\
\hline
\end{tabular}

By considering the values of G1 and G2 for each scenario, table IV summarizes the computational results of the NMOP. In our experiment, we vary the values of $\mathrm{w}$ from 0 to 1 with a step of 0.1. Usually, this factor is fixed by the decision maker, which makes the method subjective to the user.

"Take in Table IV" 
Table IV: Computational results of the NMOP

\begin{tabular}{|c|c|c|c|c|c|c|c|c|c|c|c|c|c|}
\hline 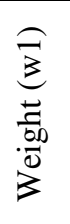 & $\bar{x}$ & $\tilde{x}$ & $\hat{x}$ & 0 & 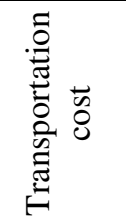 & 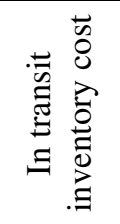 & 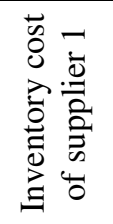 & 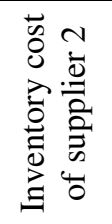 & 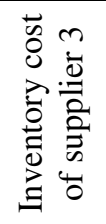 & 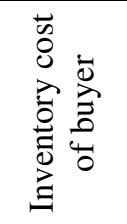 & 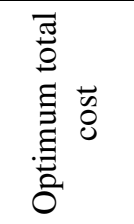 & 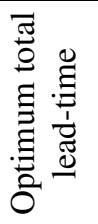 & N \\
\hline \multicolumn{14}{|c|}{ Scenario 1} \\
\hline 1 & 0.54 & 0.46 & 0 & 219 & 224.55 & 172.20 & 63.81 & 46.31 & 0 & 110.12 & 662.69 & 1.76 & 0 \\
\hline 0.9 & 0.56 & 0.44 & 0 & 218 & 225.25 & 170.79 & 68.39 & 42.17 & 0 & 110.56 & 663.04 & 1.74 & 0.0166 \\
\hline 0.8 & 0.59 & 0.41 & 0 & 216 & 226.54 & 169 & 74.24 & 37.13 & 0 & 111.37 & 664.49 & 1.72 & 0.0321 \\
\hline 0.7 & 0.62 & 0.38 & 0 & 214 & 228.91 & 166.62 & 81.99 & 30.88 & 0 & 112.87 & 668.12 & 1.70 & 0.0457 \\
\hline 0.6 & 0.67 & 0.33 & 0 & 208 & 233.51 & 163.27 & 92.78 & 23 & 0 & 115.78 & 676.37 & 1.67 & 0.0566 \\
\hline 0.5 & 0.74 & 0.26 & 0 & 197 & 243.43 & 158 & 108.97 & 13.06 & 0 & 122.03 & 696.14 & 1.61 & 0.0627 \\
\hline 0.4 & 0.89 & 0.11 & 0 & 173 & 270.77 & 147.67 & 137.20 & 2.08 & 0 & 139.28 & 754.78 & 1.51 & 0.0587 \\
\hline 0.3 & 0.90 & 0.10 & 0 & 171 & 272.82 & 147 & 138.86 & 1.72 & 0 & 140.58 & 759.31 & 1.50 & 0.0442 \\
\hline 0.2 & 0.90 & 0.10 & 0 & 171 & 272.82 & 147 & 138.86 & 1.72 & 0 & 140.58 & 759.31 & 1.50 & 0.0297 \\
\hline 0.1 & 0.90 & 0.10 & 0 & 171 & 272.82 & 147 & 138.86 & 1.72 & 0 & 140.58 & 759.31 & 1.50 & 0.0152 \\
\hline 0 & 0.90 & 0.10 & 0 & 226 & 354.26 & 147 & 183.05 & 2.26 & 0 & 185.31 & 938.26 & 1.50 & 0 \\
\hline \multicolumn{14}{|c|}{ Scenario 2} \\
\hline 1 & 0.51 & 0.49 & 0 & 583 & 566.01 & 89.72 & 150.29 & 141.29 & 0 & 291.58 & 1256.05 & 0.71 & 0 \\
\hline 0.9 & 0.52 & 0.48 & 0 & 583 & 566.50 & 89.20 & 158.84 & 132.98 & 0 & 291.83 & 1256.54 & 0.71 & 0.0184 \\
\hline 0.8 & 0.54 & 0.46 & 0 & 581 & 567.79 & 88.55 & 169.71 & 122.78 & 0 & 292.49 & 1258.53 & 0.70 & 0.036 \\
\hline 0.7 & 0.56 & 0.44 & 0 & 578 & 570.56 & 87.70 & 183.99 & 109.94 & 0 & 293.93 & 1263.40 & 0.70 & 0.0523 \\
\hline 0.6 & 0.60 & 0.40 & 0 & 573 & 576.33 & 86.54 & 203.54 & 93.36 & 0 & 296.90 & 1274.12 & 0.69 & 0.0667 \\
\hline 0.5 & 0.64 & 0.36 & 0 & 561 & 588.77 & 84.84 & 232.04 & 71.26 & 0 & 303.30 & 1298.05 & 0.67 & 0.0779 \\
\hline 0.4 & 0.72 & 0.28 & 0 & 533 & 619.23 & 82.01 & 277.82 & 41.18 & 0 & 319 & 1358.01 & 0.65 & 0.083 \\
\hline 0.3 & 0.90 & 0.10 & 0 & 457 & 721.56 & 75.76 & 366.72 & 4.99 & 0 & 371.71 & 1562.62 & 0.60 & 0.0736 \\
\hline 0.2 & 0.90 & 0.10 & 0 & 457 & 722.33 & 75.72 & 367.22 & 4.89 & 0 & 372.11 & 1564.17 & 0.60 & 0.0491 \\
\hline 0.1 & 0.90 & 0.10 & 0 & 457 & 722.33 & 75.72 & 367.22 & 4.89 & 0 & 372.11 & 1564.17 & 0.60 & 0.0245 \\
\hline 0 & 0.898 & 0.100 & 0.002 & 611 & 972.73 & 75.71 & 492.49 & 6.16 & 0.001 & 498.65 & 2070.30 & 0.60 & 0 \\
\hline \multicolumn{14}{|c|}{ Scenario 3} \\
\hline 1 & 0 & 0.54 & 0.46 & 251 & 262.93 & 246.81 & 0 & 73.19 & 53.19 & 126.38 & 802.31 & 2.47 & 0 \\
\hline 0.9 & 0 & 0.58 & 0.42 & 248 & 265.27 & 243.24 & 0 & 84.87 & 42.89 & 127.76 & 804.29 & 2.44 & 0.2364 \\
\hline 0.8 & 0.71 & 0.29 & 0 & 375 & 427.34 & 112.54 & 187.24 & 32.40 & 0 & 219.64 & 1005.80 & 1.03 & 0.2854 \\
\hline 0.7 & 0.85 & 0.15 & 0 & 333 & 472.28 & 93.01 & 239.60 & 7.73 & 0 & 247.33 & 1089.95 & 0.81 & 0.2834 \\
\hline 0.6 & 0.90 & 0.10 & 0 & 318 & 492.71 & 86.07 & 256.25 & 3.30 & 0 & 259.55 & 1129.35 & 0.73 & 0.2446 \\
\hline 0.5 & 0.90 & 0.10 & 0 & 318 & 492.72 & 86.06 & 256.25 & 3.30 & 0 & 259.55 & 1129.35 & 0.73 & 0.2038 \\
\hline 0.4 & 0.90 & 0.10 & 0 & 318 & 492.72 & 86.06 & 256.25 & 3.30 & 0 & 259.55 & 1129.35 & 0.73 & 0.1631 \\
\hline 0.3 & 0.90 & 0.10 & 0 & 318 & 492.72 & 86.06 & 256.25 & 3.30 & 0 & 259.55 & 1129.35 & 0.73 & 0.1223 \\
\hline 0.2 & 0.90 & 0.10 & 0 & 318 & 492.72 & 86.06 & 256.25 & 3.30 & 0 & 259.55 & 1129.36 & 0.73 & 0.0815 \\
\hline 0.1 & 0.90 & 0.10 & 0 & 318 & 492.72 & 86.06 & 256.25 & 3.30 & 0 & 259.55 & 1129.36 & 0.73 & 0.0408 \\
\hline 0 & 0.90 & 0.10 & 0 & 318 & 492.72 & 86.06 & 256.25 & 3.30 & 0 & 259.55 & 1129.36 & 0.73 & 0 \\
\hline
\end{tabular}




\begin{tabular}{ccccccccccccccc}
\hline \multicolumn{10}{c}{ Scenario 4 } \\
\hline 1 & 0.58 & 0 & 0.42 & 233 & 246.48 & 202.95 & 78.58 & 0 & 41.08 & 119.67 & 731.62 & 2.03 & 0 \\
0.9 & 0.65 & 0 & 0.35 & 227 & 252.41 & 192.66 & 95.37 & 0 & 27.91 & 123.28 & 735.79 & 1.93 & 0.1043 \\
0.8 & 0.75 & 0 & 0.25 & 212 & 266.49 & 177.84 & 118.38 & 0 & 13.48 & 131.86 & 755.28 & 1.791 & 0.1951 \\
0.7 & 0.90 & 0 & 0.10 & 185 & 298.42 & 155 & 149.46 & 0 & 1.85 & 151.31 & 810.24 & 1.57 & 0.2617 \\
0.6 & 0.90 & 0 & 0.10 & 185 & 298.42 & 155 & 149.46 & 0 & 1.85 & 151.31 & 810.24 & 1.57 & 0.3131 \\
0.5 & 0.36 & 0.64 & 0 & 455 & 486.85 & 119.50 & 58.72 & 186.71 & 0 & 245.44 & 1119.21 & 1.06 & 0.3137 \\
0.4 & 0.29 & 0.71 & 0 & 436 & 503.55 & 117.33 & 37.11 & 218.83 & 0 & 255.95 & 1155.70 & 1.03 & 0.2666 \\
0.3 & 0.20 & 0.80 & 0 & 405 & 536.37 & 114.40 & 16.21 & 259.32 & 0 & 275.53 & 1226.51 & 0.97 & 0.2058 \\
0.2 & 0.20 & 0.80 & 0 & 405 & 536.37 & 114.40 & 16.21 & 259.32 & 0 & 275.53 & 1226.51 & 0.97 & 0.1386 \\
0.1 & 0.20 & 0.80 & 0 & 405 & 536.37 & 114.40 & 16.21 & 259.32 & 0 & 275.53 & 1226.51 & 0.97 & 0.0714 \\
0 & 0.20 & 0.80 & 0 & 402 & 545.23 & 143.40 & 16.09 & 257.43 & 0 & 273.52 & 1226.51 & 0.97 & 0 \\
\hline & & & & & \multicolumn{1}{c}{ Scenario 5 } & & & & & 0 \\
\hline 1 & 0.54 & 0.46 & 0 & 219 & 224.55 & 172.20 & 63.81 & 46.31 & 0 & 110.12 & 662.69 & 1.76 & 0 \\
0.9 & 0.56 & 0.44 & 0 & 218 & 225.44 & 170.48 & 69.40 & 41.28 & 0 & 110.68 & 663.22 & 1.74 & 0.0421 \\
0.8 & 0.60 & 0.40 & 0 & 216 & 227.17 & 168.28 & 76.59 & 35.19 & 0 & 111.78 & 665.39 & 1.72 & 0.0824 \\
0.7 & 0.64 & 0.36 & 0 & 212 & 230.52 & 165.33 & 86.19 & 27.70 & 0 & 113.89 & 670.88 & 1.69 & 0.1201 \\
0.6 & 0.70 & 0.30 & 0 & 204 & 237.29 & 161.06 & 99.71 & 18.46 & 0 & 118.16 & 683.71 & 1.64 & 0.1535 \\
0.5 & 0.80 & 0.20 & 0 & 188 & 253.03 & 153.96 & 120.61 & 7.48 & 0 & 128.09 & 716.30 & 1.57 & 0.1793 \\
0.4 & 0.90 & 0.10 & 0 & 171 & 272.82 & 147 & 138.86 & 1.71 & 0 & 140.57 & 759.31 & 1.50 & 0.1905 \\
0.3 & 0.90 & 0.10 & 0 & 171 & 272.82 & 147 & 138.86 & 1.71 & 0 & 140.57 & 759.31 & 1.50 & 0.1979 \\
0.2 & 0.33 & 0 & 0.67 & 510 & 564.21 & 134.66 & 56.42 & 0 & 227.17 & 283.59 & 1285.66 & 1.24 & 0.1922 \\
0.1 & 0.30 & 0 & 0.69 & 499 & 574.25 & 134.40 & 44.94 & 0 & 244.70 & 289.64 & 1307.96 & 1.22 & 0.0996 \\
0 & 0.30 & 0.003 & 0.697 & 532 & 584.47 & 134.61 & 47.71 & 0.005 & 258.59 & 306.32 & 1343.66 & 1.23 & 0 \\
\hline
\end{tabular}

From these computational results of our model, we can deduce the following remarks:

- When suppliers use all the same type of shipment, (scenarios 1 and 2), suppliers to select are 1 and 2.

- For other scenarios, these results illustrate that varying the weights of the criteria will result in different suppliers being selected with varying order quantities. Indeed, for scenario 3, the buyer will choose suppliers 2 and 3 if w takes values 1 or 0.9 and suppliers 1 and 2 if $w$ takes other values. For scenario 4, the choice will relate to suppliers 1 and 3 if $\mathrm{w}$ varies from 0.6 to 1 and suppliers 1 and 2 if $\mathrm{w}$ varies from 0 to 5 . Finally, for scenario 5, the buyer will select suppliers 1 and 2 if $w$ varies from 0.3 to 1 , suppliers 1 and 3 if $w$ takes values 0.1 or 0.2 and all suppliers if $w=0$.

- For a given value of $\mathrm{w}$, for example $\mathrm{w}=0.5$, the minimum of all the $\mathrm{Z}$ is reached for scenarios 1 . The buyer will choose suppliers 1 and 2 . In both scenarios, suppliers use a LTL shipment type, which gives a minimum transportation cost (243.43) with a percentage of $35 \%$ of the total cost. The optimum order allocations assigned to each supplier are respectively, in proportion 0.74 and 0.26 . The optimum order quantity is 197 and the order quantities, which should be purchased from suppliers 1 and 2, respectively are 146 and 51 for each of the five periods because there are D/Q (=5.08) periods. At the 
6th period, the buyer may order the rest of quantities to buyer 1 (15) to satisfy the demand.

"Take in Figure 1".

- The in-transit inventory cost is maximum for selected suppliers whereas it's minimum for the same case, for the other scenarios and especially for scenarios 2, 3 and 4. Indeed, a TL is faster and thus the products remain less longer in the road.

- Conversely, the inventory cost of buyer is minimum for scenarios 1 and 5 whereas it's significant for scenario 4 , then for scenario 3 and more significant for scenario 2 . The use of a TL implies that the products arrive quickly to the buyer and its stock is maximum.

- For each scenario and for the selected suppliers, the inventory cost increases in the same direction as $\mathrm{w}$ for one while it decreases for the other.

Inventory level

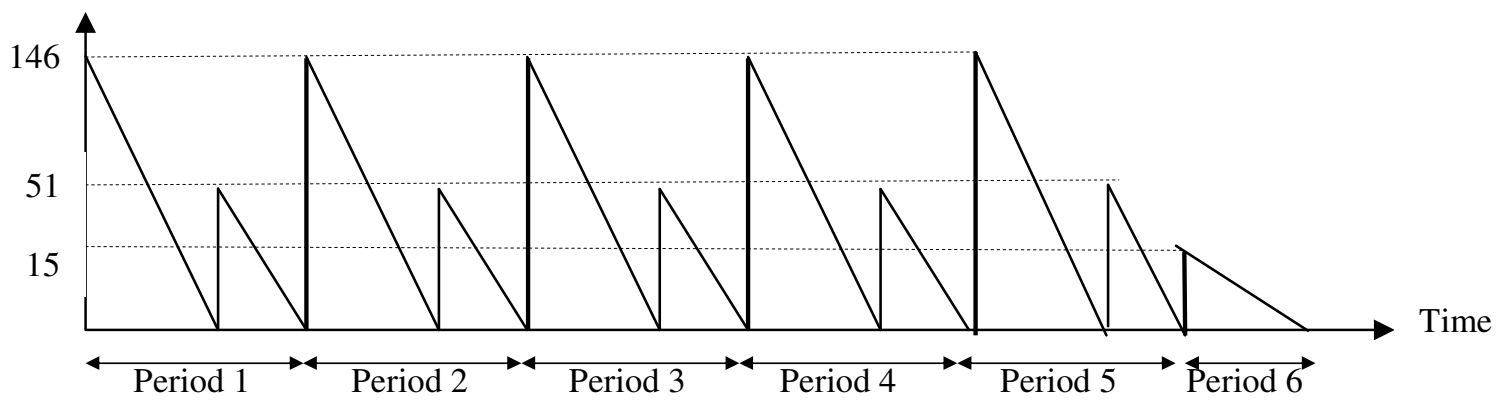

Figure 1. Average inventory of the buyer

\section{Conclusions}

In a multiple sourcing network, the buyer has to employ more suppliers concurrently. In this case, several problems arise such as the determination of the optimal number of suppliers and the portion of the order to allocate to each one.

In reviewing the literature on this area, we note that there has been very little work that comprehensively examines the role of the transportation in this selection.

In this research, we have developed and demonstrated the use of a multiobjective programming approach for improving the impact of transportation in supplier selection problem. Our model can assist the buyer in selecting the appropriate suppliers to employ and determining the order quantities to split among them.

The proposed comprehensive approach is also likely to find multiple solutions to the problem, each corresponding to a different setting of the weight factor and to the type of shipment used to move products from selected suppliers to buyer.

\section{References}

Aguezzoul, A. and Ladet, P. (2004a). A nonlinear multiobjective approach for the supplier selection taking into account transportation. Proceedings of International conference on MultiObjective Programming and Goal Programming "New Trends and Applications" (MOPGP'04), April 14-16, Hammamet - Tunisia. 
Aguezzoul, A. and Ladet, P. (2004b). A multiobjective approach to vendor selection taking into account transportation. Proceedings of the $2^{\text {nd }}$ World on Production and Operations Management Society (POMS) Conference, April 30- May 3, Cancun - Mexico.

Aguezzoul, A. and Ladet, P. (2004c). A multiobjective approach for Supplier selection, integrating shipment types. Proceedings of the IEEE Conférence Internationale Francophone d'Automatique (CIFA), November 22-24, Douz - Tunisia.

Burns, L. D., Hall, R. W., Blumenfeld, D. E. and Daganzo, C. F. (1985). Distribution strategies that minimize transportation and inventory costs. Operations Research. Vol 33 No 3, pp. 469489.

Çebi, F. and Bayraktar, D. (2003). An integrated approach for supplier selection. Logistics Information Management, Vol 16 No 6, pp. 395-400.

Chaudhry, S.S., Forst, F.G. and Zydiak, J.L. (1993). Vendor selection with price breaks. European Journal of Operational Research, Vol 70, pp. 52-66.

Dickson, G. W. (1966). An analysis of vendor selection systems and decisions. Journal of Purchasing, Vol 2 No 1, pp. 5-17.

Ganeshan, R., Tyworth, J. E. and Guo, Y. 1999. Dual sourced supply chains the discount supplier option. Transportation Research, No 35, pp. 11-23.

Goffin, K., Szwejczewski, M. and New, C. (1997). Managing suppliers: when fewer can mean more. International Journal of physical Distribution \& Logistics Management, Vol 27 No 7, pp. 422-436

Ghodsypour, S. H. and O'Brien, C. (2001). The total cost of logistics in supplier selection, under conditions of multiple sourcing, multiple criteria and capacity constraint. International Journal of Production Economics, No 73, pp.15-27

Hall, R. W. (1985). Dependence between shipment size and mode in freight transportation. Transportation Science, Vol 9 No 4, pp. 436-444.

Hong, J. D. and Hayya, J. C. (1992). Just-In-Time purchasing: Single or multiple sourcing? International Journal of Production Economics, No 27, pp. 175-181.

Liu, J., Ding, F. Y. and Lall, V. (2000). Using data envelopment analysis to compare suppliers for supplier selection and performance improvement. Supply Chain Management: An International Journal, Vol 5 No 3, pp. 143-150.

Mondal, A. and Deshmukh, S. G. 1994. Vendor selection using Interpretive Structural modeling (ISM). International Journal of Operations \& Production Management, Vol 14 No 6, pp. 52-59.

Pan, A. (1989). Allocation of order quantity among suppliers. Journal of Purchasing and Materials Management, Vol 25 No 3, pp. 36-39.

Jayaraman, V., Srivastava, R. and Benton, W.C. (1999). Supplier selection and order quantity allocation: a comprehensive model. The Journal of Supply Chain Management, pp. 50-58.

Sarkis, J. and Srinivas, T. (2002). A model for strategic supplier selection. The Journal of Supply Chain Management, Vol 38 No 1, pp. 18-28.

Sedarage, D., Fujiwara, O. and Luong, H. T. (1999). Determining optimal splitting and reorder level for N-supplier inventory systems. European Journal of Operational Research, 116, pp. 389404. 
Teng, S. G. and Jaramillo, H. (2005). A model for evaluation and selection of suppliers in global textile and apparel supply chains. International Journal of Physical Distribution \& Logistics Management, Vol 35 No 7, pp. 503-523.

Tyworth, J. E. and Ruiz-Torres, A. (2000). Transportation' role in the sole-versus dual sourcing decision. International Journal of Physical Distribution \& Logistics Management, Vol 30 No 2, pp. 128-144.

Vokurka, R. J., Choobineh, J. and Vadi, L. 1996. A prototype expert system for the evaluation and selection of potential suppliers. International Journal of Operations \& Production Management, Vol 16 No 12, pp. 106-127.

Weber, C. A., Current, J. and Benton, W. C. (1991). Vendor selection criteria and methods. European Journal of Operational Research, No 50, pp. 2-18.

Weber, C. A. and Ellram, L. M. (1993). Supplier Selection Using Multi-objective Programming: A Decision Support System Approach. International Journal of Physical Distribution \& Logistics Management, Vol 23 No 2.

Weber, C. A (1996). A data envelopment analysis approach to measuring vendor performance. Supply Chain Management, Vol 1 No 1, pp. 28-39.

Weber, C. A., Current, J. and Desai, A. (2000). An optimization approach to determining the number of vendors to employ. Supply Chain Management: An International Journal, Vol 5 No 2, pp. 90-98.

Youssef, M. A., Zairi, M. and Mohanty, B. (1996). Supplier selection in an advanced manufacturing technology environment: an optimization model. Benchmarking for quality Management \& Technology, Vol 3 No 4, pp. 60-72. 